\title{
Structural Transformation of Template-Synthesized Mesoporous Silica with Addition of Chloroform
}

\author{
Yoshio KOBAYASHI and Maryanne M. COLLINSON* \\ Department of Chemical Engineering, Graduate School of Engineering, Tohoku University, \\ 07 Aoba, Aramaki, Aoba-ku, Sendai-shi 980-8579 \\ *Department of Chemistry, Kansas State University, Manhattan, Kansas 66506, USA \\ クロロホルム添加による鋳型合成メソポーラスシリカの構造変化 \\ 小林芳男 · Maryanne M. Collinson* \\ 東北大学大学院工学研究科化学工学専攻, 980-8579 仙台市青葉区荒巻字青葉 07 \\ ${ }^{*}$ Department of Chemistry, Kansas State University, Manhattan, Kansas 66506, USA
}

\begin{abstract}
M41S family mesoporous silica materials were synthesized via the hydrolysis and condensation of tetraethylorthosilicate (TEOS) using cetyltrimethylammonium bromide (CTAB) as a template and sodium hydroxide as a catalyst. MCM-48 and MCM-41 were prepared in the absence and in the presence of chloroform, respectively. The addition of chloroform likely changed both aggregation and swelling behavior of CTAB micelles and consequently hexagonal mesoporous structures were formed.
\end{abstract}

[Received January 16, 2004; Accepted March 23, 2004]

Key-words:Mesoporous silica, Template, M41S, Tetraethylorthosilicate, Sol-gel method, Chloroform, Cetyltrimethylammonium bromide

\section{Introduction}

Since workers at Mobil prepared ordered mesoporous materials with template-synthesis (the so-called M41S family), 1),2) various kinds of preparation procedures have been reported. The M41S family silica materials are typically prepared by heating a silica source with surfactant, catalyst such as acid or base, water, and alcohol at $100-150^{\circ} \mathrm{C}$. The M41S family is made up of three well-defined mesostructures: MCM-41, MCM-48 and MCM-50. ${ }^{3)}$ MCM-41 possesses a hexagonally packed array of noninterconnenting cylindrical pores. The structure of MCM-48 belongs to the cubic space group. MCM-50 contains a lamellar structure in uncalcined form. The structure of the M41S silica materials is mainly dependent on a surfactant concentration, because silica formation takes place on hydrophilic groups of the micelle whose structure is related to the surfactant concentration. ${ }^{1,2), 4)}$ Generally, the structure of micelle dispersed in water may be governed by not only the surfactant concentration but also addition of hydrophobic agents, because the hydrophobic agent is incorporated in the micelle. Cosolvents have also been shown to affect the aggregation behaviour of micelles in solution. ${ }^{5)-7)}$ In this note, we show what a large effect a small amount of chloroform has on the structure of M41S materials.

\subsection{Chemicals}

\section{Experiment}

CTAB (Aldrich), sodium hydroxide (Fisher), tetraethylorthosilicate (TEOS) (Aldrich) and chloroform (Fisher) were used as received. Water was purified to Type I using a Labconco Water Pro PS four-cartridge system.

\subsection{Synthesis}

CTAB, sodium hydroxide, TEOS and chloroform were used as surfactant, catalyst, silica source and the additive, respectively. To $1.74 \mathrm{~g}$ of $\mathrm{CTAB}$ and $0.3 \mathrm{~mL}$ of chloroform that were dissolved in $36.8 \mathrm{~mL}$ of water was added $10 \mathrm{~mL}$ of $1 \mathrm{M}$ aqueous sodium hydroxide and $4.6 \mathrm{~mL}$ of TEOS un- der vigorously stirring at room temperature. The molar ratio of CTAB, sodium hydroxide, TEOS, water and chloroform was $0.24: 0.5: 1: 130: 0.35$, respectively. The mixture was aged in an oven at $100^{\circ} \mathrm{C}$ for $24 \mathrm{~h}$. The white powder was then filtered, washed with water, and dried in air at $100^{\circ} \mathrm{C}$ for $12 \mathrm{~h}$. The white powder finally was heated in air at $550^{\circ} \mathrm{C}$ for $5 \mathrm{~h}$. The heating rate from room temperature to $550^{\circ} \mathrm{C}$ was $2^{\circ} \mathrm{C}$ / min, leading to removal of chloroform and CTAB. For comparison, chloroform-free materials were also synthesized in a similar fashion only $\mathrm{CHCl}_{3}$ was not added.

\subsection{Characterization}

XRD measurements were performed with Scintag XDS 2000 using Ni-filtered $\mathrm{Cu} \mathrm{K} \alpha$ radiation. Slits widths starting from the X-ray source were $0.05,0.01,1,0.2 \mathrm{~mm}$. Tube voltage and current were $40 \mathrm{kV}$ and $40 \mathrm{~mA}$, respectively. Transmission electron microscope (TEM) was performed with Philips CM 100 operated at $100 \mathrm{kV}$ accelerating voltage. Samples for TEM were prepared by grinding the powder samples with a mortal, suspending them into $95 \%(v / v)$ ethanol/water, dropping the suspension onto the top of a polymer-coated copper grid and drying.

\section{Results and discussion}

A typical TEM image of the mesoporous silica (sample 4) is shown in Fig. 1. It exhibited a very well ordered structure of mesopores.

Figure 2 shows XRD patterns of silica synthesized in the absence of chloroform. For the unannealed sample (sample 1), two dominant diffraction peaks were clearly observed at 2.79 and $3.20^{\circ}$, which matched well, respectively, with (211) and (200) planes in the cubic Ia3d space group reported XRD data on MCM-48..$^{1), 8)}$ The annealing at $550^{\circ} \mathrm{C}$ (sample 2) shifted these peaks to angles as high as 2.92 and $3.36^{\circ}$, respectively. A weak peak was faintly observed in the range of 5$5.5^{\circ}$, as-shown in the extended pattern. This peak might be composed of other Ia3d phase peaks such as (420) and (322) 


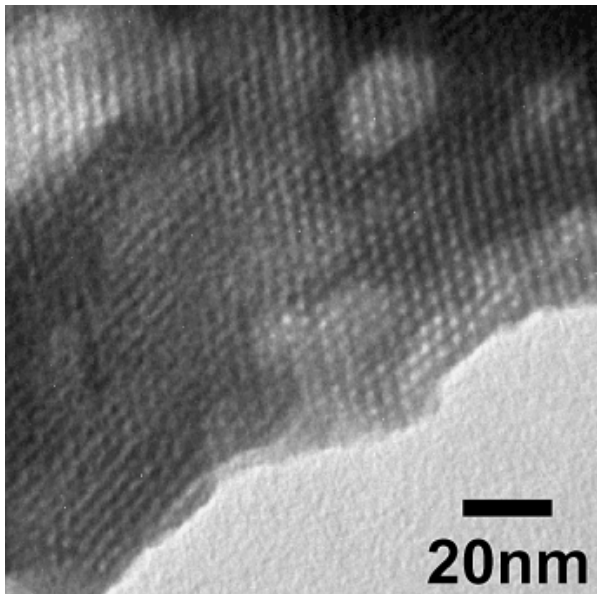

Fig. 1. TEM image of silica synthesized in the presence of chloroform (sample 4$)$.

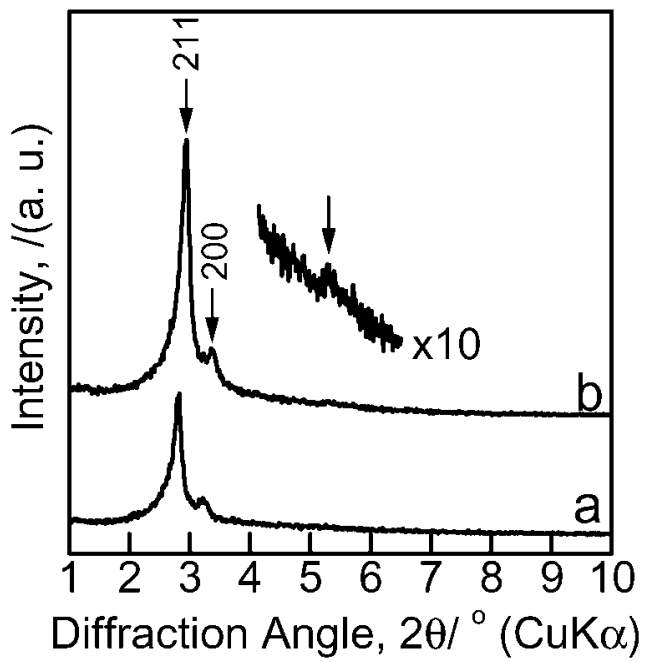

Fig. 2. XRD patterns of silica synthesized in the absence of chloroform. (a) unannealed, (b) annealed in air at $550^{\circ} \mathrm{C}$ for $3 \mathrm{~h}$.

Table 1. Effect of Addition of Chloroform and Annealing on $d$-Spacing and Lattice Constant

\begin{tabular}{lllll}
\hline name & chloroform & annealing & $d$-spacing /nm & $\mathrm{a}_{0}$ \\
\hline \hline sample 1 & none & none & $0.316(d(211))$ & 7.74 \\
sample 2 & none & performed & $0.302(d(211))$ & 7.40 \\
sample 3 & added & none & $0.399(d(100))$ & 4.61 \\
sample 4 & added & performed & $0.391(d(100))$ & 4.51 \\
\hline
\end{tabular}

planes. Values of $d$-spacing corresponding to the diffraction angle of the (211) plane $(d(211))$ and of lattice constant, $a_{0}$, calculated from the $d(211)$ are summarized in Table 1. The lattice constant, $a_{0}$, was obtained from an equation of $a_{0}=d$ $(211) \times \sqrt{2^{2}+1^{2}+1^{2}}$. The $d(211)$ values decreased from 0.316 to 0.302 by annealing, which indicated that the annealing shrank the structure of mesoporous silica. Intensities of the XRD peaks increased with the annealing due to higher scattering contrast between pore walls and inside of the pores caused by the burning-out of the templating organic species. ${ }^{9)}$

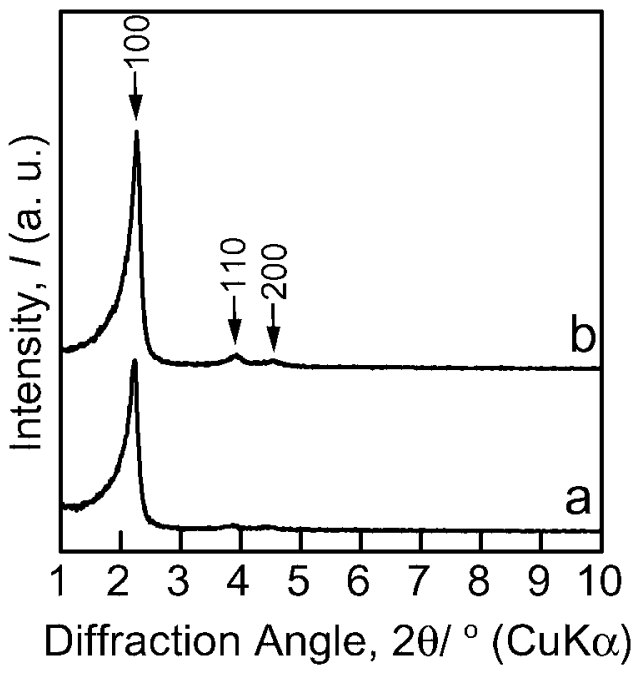

Fig. 3. XRD patterns of silica synthesized in the presence of chloroform. (a) unannealed, (b) annealed in air at $550^{\circ} \mathrm{C}$ for $3 \mathrm{~h}$.

Figure 3 shows XRD patterns of silica synthesized in the presence of chloroform. For the unannealed sample (sample 3 ), three dominant diffraction peaks were clearly observed at $2.21,3.85$ and $4.45^{\circ}$, which were assigned, respectively, to (100), (110) and (200) planes in the hexagonal phase of MCM-41. The annealing at $550^{\circ} \mathrm{C}$ (sample 4) shifted these peaks to higher angles of $2.26,3.90$ and $4.52^{\circ}$, respectively. Table 1 summarizes values of $d$-spacing $(d(100))$ and of lattice constant, $a_{0}$, calculated from an equation of $a_{0}=$ $d(100) \times \sqrt{4 / 3}$. A decrease in the $d(100)$ and $a_{0}$ values and an increase in all intensities of the XRD peaks with the annealing were also obtained as well as in the absence of chloroform.

The addition of chloroform transformed the structure of the mesoporous silica from cubic (MCM-48) to hexagonal (MCM-41). In previous work, the presence of organic additives such as dopant molecules and cosolvent changed the resulting structure of mesoporous silica from hexagonal to lamellar, ${ }^{5)-7)}$ opposite to what we have observed. Chloroform, which was used in our work, is insoluble in water and nonprotic, and does not have electron-donating ability. In addition, dielectric constant of chloroform is smaller than that of methylene chloride that was used as a cosolvent in Anderson et al.'s work..$^{5)}$ Therefore, this additive likely resides almost exclusively in the interior of the micelles thus swelling it and even changing its aggregation behavior. The addition of chloroform probably led to formation of the CTAB aggregation whose behavior was different from the prior references, ${ }^{5)-7)}$ and consequently hexagonal mesoporous structures were formed. Further investigation is now in progress.

\section{Conclusion}

The addition of chloroform led to structural transformation from cubic to hexagonal during preparation of M41S family mesoporous silica using CTAB, sodium hydroxide, TEOS and water.

Acknowledgments We express our thanks to Dr. A. Q. Paulsen and Dr. D. L. Boyle of the Division of Biology, Kansas State University, for their help for TEM observation and ONR for financial support. 


\section{References}

1) Kresge, C. T., Leonowicz, M. E., Roth, W. J., Vartuli, J. C. and Beck, J. S., Nature, Vol. 359, pp. 710-712 (1992).

2) Beck, J. S., Vartuli, J. C., Roth, W. J., Leonowicz, M. E., Kresge, C. T., Schmitt, K. D., Chu, C. T.-W., Olson, D. H., Sheppard, E. W., McCullen, S. B., Higgins, J. B. and Schlenker, J. L., J. Am. Chem. Soc., Vol. 114, pp. 10834-10843 (1992).

3) Ying, J. Y., Mehnert, C. P. and Wong, M. S., Angew. Chem. Int. Ed., Vol. 38, pp. 56-77 (1999).

4) Vartuli, J. C., Kresge, C. T., Roth, W. J., Leonovicz, M. E., McCullen, S. B., Hellring, S. D., Beck, J. B., Schlenker, J. L., Olsen, D. H. and Sheppard, E. W., Chem. Mater., Vol. 6, pp.
2317-2326 (1994).

5) Anderson, M. T., Martin, J. E., Odinek, J. G. and Newcomer, P. P., Chem. Mater., Vol. 10, pp. 311-321 (1998).

6) Huang, M. H., Kartono, F., Dunn, B. and Zink, J. I., Chem. Mater., Vol. 14, pp. 5153-5162 (2002).

7) Garcia M., J. A., Valverde, G. and Zink, J. I., Langmuir, Vol. 19, pp. 4411-4414 (2003).

8) Kumar, D., Bera, S., Tripathi, A. K., Dey, G. K. and Gupta, N. M., Macro. Meso. Mater., Vol. 66, pp. 157-167 (2003).

9) Pantazis, C. C., Trikalitis, P. N., Pomonis, P. J. and Hudson, M. J., Macro. Meso. Mater., Vol. 66, pp. 37-51 (2003). 